\title{
Negotiation, bargaining, and discounts: generating WoM and local tourism development at the Tabriz bazaar, Iran
}

Jamie Thompson, lan W. F. Baxter, Ross Curran, Martin J. Gannon, Sean Lochrie, Babak Taheri and Ozge Yalinay

This is an Accepted Manuscript of an article published by Taylor \& Francis in Current Issues in Tourism on $2^{\text {nd }}$ November 2017, available online: wwww.tandfonline.com/10.1080/13683500.2017.1396294 


\section{Negotiation, Bargaining, and Discounts: Generating WoM and Local Tourism Development at the Tabriz Bazaar, Iran}

This paper examines the effects of negotiation intention, bargaining propensity, and discount satisfaction on word-of-mouth (WoM) behaviours for tourists visiting Tabriz bazaar, Iran. Data from 615-survey respondents highlights that tourists are motivated to conduct WoM behaviour when they are experientially satisfied with the opportunity to negotiate and bargain, and when they are satisfied with the discount they receive. This paper makes theoretical contributions to Social-Exchange-Theory and presents managerial implications for policy-makers to generate tourism development.

Keywords: bargaining; negotiation; satisfaction; word-of-mouth; social-exchangetheory 


\section{Introduction}

Tourism in Iran faces challenges rooted in political turbulence, conflict, and cultural and religious restrictions (Pratt \& Alizadeh, 2017; Yazdi, Salehi \& Soheilzad, 2017), and policymakers must develop sustainable tourism that benefits the region and the local people directly involved in its provision (Ahadian, 2013; Pratt \& Alizadeh, 2017). One opportunity for this stems from street markets and bazaars, which encourage tourists to engage and directly purchase from local sellers, while also providing opportunities to assimilate into local culture (Muzaini, 2006).

Drawing from social exchange theory (SET) (Ap, 1992; Emerson, 1976), this paper assesses how bargaining and negotiation exchanges lead to word-of-mouth (WoM) intentions. SET is a framework that conceptualises relationships as an exchange of resources in return for benefits to the self (Emerson, 1976). While SET has been used to frame attitudes towards tourism (Ap, 1992; Nunkoo \& Ramikissoon, 2010), it has yet to be considered in street-market settings, despite their reliance on negotiated and reciprocal exchange (Alavi, Wieseke \& Guba, 2016). Extant research recognises the role of homophily in stimulating effective WoM (Groeger \& Buttle, 2014), and how positive WoM can enhance destination image and destination awareness (Hernández-Méndez, Muñoz-Leiva \& Sánchez-Fernández, 2015), suggesting that tourists are an appropriate target for generating WoM behaviour.

\section{Research framework and hypotheses}

Emerson (1976, p.336) considers social exchanges as "two-sided, mutually contingent, and mutually rewarding processes involving 'transactions"'. Lawler, Thye, and Yoon (2008) identify two forms of direct exchange: negotiated exchange and reciprocal exchange. Negotiated Exchange is a multilateral engagement where parties explicitly decide upon the terms of exchange in order to construct a mutually beneficial relationship (Molm, Peterson \& Takahashi, 2003). Reciprocal Exchange, in contrast, is sequential (Lawler et al., 2008), is devoid of any immediate implication to return the exchange, but relies on one party to reciprocate (Lee \& Hyun, 2016; Molm et al., 2003).

Negotiated exchanges can be distributive, where parties attempt to reach an asymmetrical discount, or integrative where cooperation can be mutually beneficial (Murphy, 2001). If the amount of money saved and percentage discount achieved are both high following a negotiated exchange, this can engender both 'discount satisfaction' (Darke, Freedman \& Chaiken, 1995) and 'experience satisfaction' in consumers if the integrated bargaining activities are considered 'fair' (Darke \& Dahl, 2003). Tourists are likely to revisit a seller when they receive discounts (Tsang, Tsai, and Leung, 2011), and may feel obliged to conduct reciprocal exchanges by recommending a seller to others when they receive good service (Murphy, 2001). Further, tourists are in an enjoyment context, where both environment and experience contribute to reciprocal WoM intentions (Vega-Vázquez, Castellanos-Verdugo \& Oviedo-García, 2015).

Negotiation intention is the purposeful instigation of strategy in order to receive a discount, while general bargaining propensity is defined as when customers have a positive attitude towards negotiating activities (Wieseke et al., 2014). Those who crave the opportunity to bargain and relish such interactions pursue opportunities to use their negotiating skills (Holmes, Beitelspacher, Hochstein \& Bolander, 2017; Schneider, Rodgers \& Bristow 1999). Similarly, tourists who enjoy the activity will negotiate on all items, and possess an array of tactics and strategies to employ, while those who consider negotiating stressful will actively avoid it (Wu, Wall \& Pearce, 2014). Therefore: 
H1: General bargaining propensity is positively related to negotiation intention.

For tourists, the experience of bargaining over price can be enjoyable, stimulating experiential satisfaction (McKercher \& Lui, 2013). Further, after negotiating when travelling, positive perceptions of ultimate price paid can elicit feelings of discount satisfaction (Correia \& Kozak, 2016). Wu et al. (2014) suggest that this is due to buyers possessing a sense of pride over their ability to negotiate. Tsang et al. (2011) find the more intense the bargaining behaviour exhibited by the individual, the greater the satisfaction they receive. Intense bargaining is perceived as a challenge, with tourists feeling a sense of victory when receiving a discount, producing associative positive feelings of satisfaction and intentions to revisit (Cetin \& Bilgihan, 2016; Kozak, 2016). Thus:

H2: Negotiation intention is positively related to discount satisfaction.

H3: General bargaining propensity is positively related to discount satisfaction.

WoM influences tourists' behaviour and buying decisions. Previous studies note that the interaction and emotional connection with the people, place, and activities engaged in at tourist destinations or cultural places impact upon tourists' behaviour and subsequent WoM intentions (Alves et al. 2016). Tourists who are satisfied with their shopping experience are more likely to recommend their experience through WoM (Vega-Vázquez et al., 2015). Accordingly, tourists who purchase products for a negotiated price are more likely to engage in WoM (Correia \& Kozak, 2016). The process of negotiating and bargaining in street markets is beneficial to psychological well-being, leading to satisfied tourists with a high likelihood of recommending the market to others (Kozak, 2016; Tsang et al., 2011; Wieseke, et al., 2014). Tourists who experience fun and enjoyment when negotiating are likely to inform others of their experience through eWoM, with two thirds of visitors to Beijing silk markets boasting of discounts received at street markets (Wu et al., 2014). Therefore, we predict:

H4: Discount satisfaction is positively related to WoM.

H5: Negotiation intention is positively related to WoM.

H6: General bargaining propensity is positively related to WoM.

\section{[Figure 1 here]}

\section{Methodology}

Survey data was collected from international tourists visiting the Tabriz bazaar in 2015. A permanent marketplace, where goods and services have been traded for hundreds of years, the historical bazaar in Tabriz is one of the Silk Road's most important economic landmarks (UNESCO, 2016). Bazaars are distinct from contemporary shopping centres as they offer the opportunity to trade through negotiating and bargaining (Wu et al., 2014) and, as loci of interpersonal selling, bazaars negate middlemen, improve moral conditions, and promote social interaction (Wu et al., 2014).. A pilot study was conducted with a sample of 40 tourists, and some items were modified following this phase. Overall, 615 surveys were collected over a three-month period. Respondents were demographically diverse, with 43.4\% (Middle-East and Asia), $43.3 \%$ (EU), and $13.3 \%$ (other). $40.2 \%$ of participants were female, and the rest male. 
$36.7 \%$ of respondents were aged $18-35,31.7 \%$ aged $36-45$, and $31.6 \%$ of participants were aged 46 or above.

To guarantee content validity, the items were adapted from existing constructs. Sevenpoint Likert scales (from $1=$ strongly disagree to $7=$ strongly agree) were used to measure all statements. Negotiation intention, general bargaining propensity, and discount satisfaction were adapted from Weiseke, Alavi, and Habel (2014), while WoM was adapted from Maxham and Netemeyer (2002) and Salanova, Agut, and Peiró (2005).

\section{Results}

Common method variance (CMV) was examined using Harman's single-factor test. The findings of the exploratory factor analysis (EFA) detected three factors with Eigenvalues greater than 1. The highest portion of variance explicated by one factor was $40.055 \%$ (Podsakoff, MacKenzie, Lee, \& Podsakoff, 2003). As a result, the CMV was not violated. Partial least squares was used to test hypotheses. PLS was suitable because it does not require the data to be normally distributed. It is also appropriate for early stage theory building and for constructs that have not received widespread empirical attention. The test of Skewness and Kurtosis indicated the assumption of normality is violated (Hair, Hult, Ringle, \& Sarstedt, 2017).

\section{Measurement model}

Composite reliability (CR), Cronbach's $\alpha$, factor loadings, and average variance extracted (AVE) were used to assess convergent validity (Hair et al., 2017). As demonstrated in Table 1, the factor loadings, CR and $\alpha$ exceeded the obligatory threshold of 0.7 (Hair, Black, Babin, $\&$ Anderson, 2010). The AVE surpassed the threshold of 0.5 for all constructs (Hair et al., 2010). Fornell and Larcker's (1981) criterion was used, which requires a scale's AVE to be larger than the square of its biggest correlation with any scale in the correlation matrix. As shown in Table 1, the constructs met this requirement. Following Henseler, Ringle, and Sarstedt (2015), heterotrait-monotrait ratio of correlation (HTMT) approach was used. All HTMT values were below the cut-off point of 0.85 ( 0.440 to 0.711$)$, suggesting the creation of discriminant validity of the scales.

\section{[Table 1 here]}

\section{Structural model}

Hypothesised relationships among scales were tested through PLS to determine: (1) StoneGeisser's $Q^{2}$ predictive reliance $\left(Q^{2}>0\right)$, (2) $R^{2}$ values of the endogenous variables, , (3) Cohen's $f^{2}$ effect sizes $\left(f^{2}>0.02\right)$, and (4) the path coefficients, (5) Standardized Root Mean Square Residual (SRMR) model fit criterion (SRMR <0.08) (Hair et al., 2017). The results indicated that $\mathrm{SRMR}=0.066, f^{2}$ and $\mathrm{Q}^{2}$ values were above the recommended values (see Figure 2).

\section{[Figure 2 here]}

As shown in Figure 2, only H1 was rejected. Post-hoc analysis of the indirect effects was carried out. To test for mediation, Taheri, Farrington, Curran, and O'Gorman's (2017) two-step bootstrapping technique was followed. 95\% confidence interval (CI) was achieved through bootstrapping. The findings indicated that WoM was indirectly influenced by general bargaining propensity (indirect $\beta=0.312, t=5.079, p<0.001,95 \% \mathrm{CI}=[0.259,0.389]$ ) and negotiation intention (indirect $\beta=0.233, t=5.123, p<0.001,95 \% \mathrm{CI}=[0.171,0.2460]$ ). As the direct paths for both relationships were significant, the results revealed that discount 
satisfaction partially mediated the influence of general bargaining propensity and negotiation intentions on WoM.

\section{Discussion and Conclusions}

Under SET, and using PLS, this paper focused on the impact of negotiation intention, general bargaining propensity, and discount satisfaction on WoM intentions. By testing the conceptual model (Figure 1), we found no support for H1, suggesting that tourists in the bazaar are likely to engage in negotiating activities, regardless of their initial inclination to do so. While this contradicts Schneider et al. (1999), this could be as a result of Tabriz cultural norms, where all individuals are expected to negotiate in the bazaar. However, the findings indicate significant support for $\mathrm{H} 2$ and $\mathrm{H} 3$; through engaging in bargaining and negotiation, tourists are more likely to be satisfied with their purchase. There is also significant support for $\mathrm{H} 4, \mathrm{H} 5$, and H6; when tourists bargain and negotiate, and subsequently receive discounts, they are more inclined to recommend the experience to others through WoM. This suggests that purchasers may feel obliged, due to the perceived concessions and value provided by the seller, which requires reciprocation in the form of WoM.

Intention to negotiate and bargaining propensity also influence WoM intentions indirectly when mediated by discount satisfaction, suggesting that the entire experiential element of marketplace exchanges, relationships, and satisfactory outcomes contribute collectively to WoM intentions. This suggests that integrative exchanges with positive bargaining between buyers and sellers produce the best results, supporting the notion that integrative social exchanges are mutually beneficial between parties (Alavi et al., 2016). The testing of the conceptual model has furthered understanding of SET in bargaining interactions. Through analysis of exchanges, we can summarise that relationships founded upon negotiation intention and bargaining propensity led to discount satisfaction for tourists, demonstrating the existence of multilateral negotiated exchange within the bazaar context. Further, the findings demonstrate that tourists feel gratitude to sellers who offer the opportunity to negotiate, and this produces reciprocal exchange relationships where they subsequently recommend their experience to others. Tourist shoppers exist within an enjoyment context (Vega-Vázquez et al., 2015), and therefore it is only through the opportunity to conduct negotiated exchanges (by bargaining and negotiating), they have the experiential satisfaction to conduct reciprocal exchanges through WoM. By demonstrating the interconnectedness of Lawler et al.'s (2008) negotiated and reciprocal exchange in the context of Iranian bazaars we extend existing understanding of SET.

\section{Practical Contributions}

Developing tourism is of particular interest to marketplaces in Iran in their attempts to revive the local economy (Pratt \& Alizadeh, 2017). Therefore, street markets are offered as a sector of the tourism industry that provides cultural assimilation, rather than acquisition, serving to prevent exploitation of local culture (Muzaini, 2006). Previous studies note the importance of WoM communication as a cost-effective marketing tool for tourism industries (Vega-Vázquez et al., 2015), which can develop local tourism.

The findings demonstrate that those who engage in bargaining and negotiating activities are more likely to recommend the experience to other potential tourists. Therefore, Iranian bazaars can generate positive WoM by engaging in negotiated exchanges with buyers and offering an experience distinct from conventional shopping arenas (Tsang et al., 2011). Traders in the bazaar must be engaged, and willing to conduct negotiations in order to further the reputation of the market through customer WoM. Traders should consider initially inflating the 
price of goods in order to encourage tourist to bargain and negotiate. Finally, participants were not particularly satisfied with the negotiation and bargaining experience during the service encounter (i.e., low discount satisfaction mean), therefore there may be other factors influencing discount satisfaction. Future studies should employ a mixed-method approach to explore the impact of other possible constructs on discount satisfaction. Also, traders in the Bazaar should pursue other, more subtle ways to interact with visitors in order to stimulate more enjoyable negotiation interactions. .

\section{Limitations and Further Research}

This study did not employ multi-group analysis to explore the differences between tourists from different geographical locations, which may be an interesting avenue for future research. Further, the solely quantitative nature of the study allows room for qualitative investigation in order to develop understanding of the intricacies and challenges of conducting negotiated and reciprocal exchanges.

\section{References}

Ahadian, O. (2013) Residents' perceptions of tourism development - implications for small economies business: The case study of Ali Sadr, Iran. Current Issues in Tourism. 16, 97-106. doi:10.1080/13683500.2012.695340

Alavi, S., Wieseke, J. \& Guba, J.H. (2016) Saving on Discounts through Accurate Sensing Salespeople's Estimations of Customer Price Importance and Their Effects on Negotiation Success. Journal of Retailing. 92, 40-55. doi:10.1016/j.jretai.2015.08.002

Alves, S., Abrantes, J.L., Antunes, M.J., Seabra, C., \& Herstein, R. (2016). WOM antecedents in backpacker travelers. Journal of Business Research, 69, 1851-1856

Ap, J. (1992). Residents perceptions on tourism impacts. Annals of Tourism Research, 19, 665- 690. doi:10.1016/0160-7383(92)90060-3

Cetin, G. \& Bilgihan, A. (2016) Components of cultural tourists' experiences in destinations. Current Issues in Tourism. 19, 137-154. doi:10.1080/13683500.2014.994595

Correia, A. \& Kozak, M. (2016) Tourists' shopping experiences at street markets: Cross-country research. Tourism Management. 56, 85-95. doi:10.1016/j.tourman.2016.03.026

Darke, P. \& Dahl, D. (2003). Fairness and Discounts: The Subjective Value of a Bargain. Journal of Consumer Psychology. 13, 328-338. doi: 10.1207/S15327663JCP1303_13 
Darke, P., Freedman, J. L. \& Chaiken, S. (1995) Percentage Discounts, Initial Price, and Bargain Hunting: A Heuristic-Systematic Approach to Price Search Behavior. Journal of Applied Psychology. 80, 580-586. doi: 10.1037/0021-9010.80.5.580

Emerson, R. (1976) Social Exchange Theory. Annual Review of Sociology. 2, 335-362. doi:doi.org/10.1146/annurev.so.02.080176.002003

Fornell, C. \& Larcker, D.F. (1981). Evaluating structural equation models with unobservable variables and measurement error. Journal of Marketing Research. 18, 39-50. doi: $10.2307 / 3151312$

Groeger, L. \& Buttle, F. (2014). Word-of-mouth marketing: Towards an improved understanding of multi-generational campaign reach. European Journal of Marketing. 48, 1186-1208. doi: 10.1108/EJM-02-2012-0086

Hair, J.F.J., Black, W.C., Babin, B.J. \& Anderson, R.E. (2010). Multivariate Data Analysis: A Global Perspective (7th ed.). USA: Pearson.

Hair, J.F.J., Hult, G.T.M., Ringle, C.M. \& Sarstedt, M. (2014). A primer on Partial Least Squares Structural Equation Modeling (PLS-SEM). UK: Sage.

Henseler, J., Ringle, C.M. \& Sarstedt, M. (2015). A New Criterion for Assessing Discriminant Validity in Variance-based Structural Equation Modeling. Journal of the Academy of Marketing Science. 43, 115-135. doi:10.1007/s11747-014-0403-8

Hernández-Méndez, J., Muñoz-Leiva, F. \& Sánchez-Fernández, J. (2015) The influence of e-word-ofmouth on travel decision-making: consumer profiles. Current Issues in Tourism. 18, 10011021. doi:10.1080/13683500.2013.802764

Holmes, Y. M., Beitelspacher, L. K., Hochstein, B. \& Bolander, W. (2017) “Let's make a deal:” Price outcomes and the interaction of customer persuasion knowledge and salesperson negotiation strategies. Journal of Business Research . 78, 81-92 doi: 10.1016/j.jbusres.2017.04.009

Kozak, M. (2016) Bargaining behavior and the shopping experiences of British tourists on vacation. Journal of Travel \& Tourism Marketing. 33, 313-325. doi:10.1080/10548408.2015.1051199

Lawler, E., Thye, S. \& Yoon, J. (2008). Social Exchange and Micro Social Order. American Sociological Review. 73, 519-542. doi:10.1177/000312240807300401

Lee, K. \& Hyun, S.S. (2016) The effects of tourists' knowledge-sharing motivation on online tourist community loyalty: The moderating role of ambient stimuli. Current Issues in Tourism. doi:10.1080/13683500.2016.1145197

Maxham, J.G. \& Netemeyer, R.G. (2002). A longitudinal study of complaining customers' evaluations of multiple service failures and recovery efforts. Journal of Marketing, 66, 57-71. doi:10.1509/jmkg.66.4.57.18512

McKercher, B. \& Lui, S. (2013) Becoming a Tourist. International Journal of Tourism Research. 16, 399-406. doi: 10.1002/jtr.1934

Molm, L., Peterson, G. \& Takahashi, N. (2003). In the Eye of the Beholder: Procedural Justice in Social Exchange. American Sociological Review. 68, 128-152. doi:10.2307/3088905

Murphy, L. (2001) Exploring social interactions of backpackers. Annals of Tourism Research. 28, 5067. doi: 10.1016/S0160-7383(00)00003-7

Muzaini, H. (2006) Backpacking South-East Asia Strategies of "Looking Local." Annals of Tourism Research. 33, 144-161. doi:10.1016/j.annals.2005.07.004

Nunkoo, R. \& Ramikissoon, H. (2010) Small island urban tourism: A residents' perspective. Current Issues in Tourism. 13, 37-60. doi:10.1080/13683500802499414

Podsakoff, P.M., MacKenzie, S.M., Lee, J. \& Podsakoff, N.P. (2003). Common method variance in behavioral research: a critical review of the literature and recommended remedies. Journal of Applied Psychology. 88, 879-903. doi:10.1037/0021-9010.88.5.879

Pratt, S. \& Alizadeh, V. (2017) The economic impact of the lifting of sanctions on tourism in Iran: A computable general equilibrium analysis. Current Issues in Tourism. doi:10.1080/13683500.2017.1307329

Salanova, M., Agut, S., \& Peiró, J.M. (2005). Linking organizational resources and work engagement to employee performance and customer loyalty: The mediation of service climate. Journal of Applied Psychology, 90, 1217-1227. doi:10.1037/0021-9010.90.6.1217 
Schneider, K.C., Rodgers, W.C. \& Bristow, D.N. (1999) Bargaining over the price of a product: Delightful anticipation or abject dread? Journal of Product \& Brand Management. 8, 232244. doi: $10.1108 / 10610429910272538$

Taheri, B., Farrington, T., Curran, R. \& O`Gorman, K.D. (2017). Sustainability and the authentic experience. Harnessing brand heritage - a study from Japan. Journal of Sustainable Tourism. doi:10.1080/09669582.2017.1310867

Tsang, N.K.F., Tsai, H. \& Leung, F. (2011) A Critical Investigation of the Bargaining Behavior of Tourists: The Case of Hong Kong Open-Air Markets. Journal of Travel \& Tourism Marketing. 28, 27-47. doi:10.1080/10548408.2011.535442

UNESCO. (2016). Tabriz Historic Bazaar Complex. Retrieved from: http://whc.unesco.org/en/list/1346

Vega-Vázquez, M., Castellanos-Verugo, M. \& Oviedo-García, M.Á. (2015) Shopping value, tourist satisfaction and positive word of mouth: The mediating role of souvenir shopping satisfaction. Current Issues in Tourism. doi:10.1080/13683500.2014.996122

Wieseke, J., Alavi, S. \& Habel, J. (2014) Willing to Pay More, Eager to Pay Less: The Role of Customer Loyalty in Price Negotiations. Journal of Marketing. 78, 17-37. doi:10.1509/jm.13.0104

Wu, M., Wall, G. \& Pearce, P. (2014) Shopping experiences: International tourists in Beijing's Silk Market. Tourism Management. 41, 96-106. doi:10.1016/j.tourman.2013.09.010

Yazdi, S.K., Salehi, K.H. \& Soheilzad, M. (2017) The relationships between tourism, foreign direct investment and economic growth: Evidence from Iran. Current Issues in Tourism. 20, 15-26. doi:10.1080/13683500.2015.1046820 


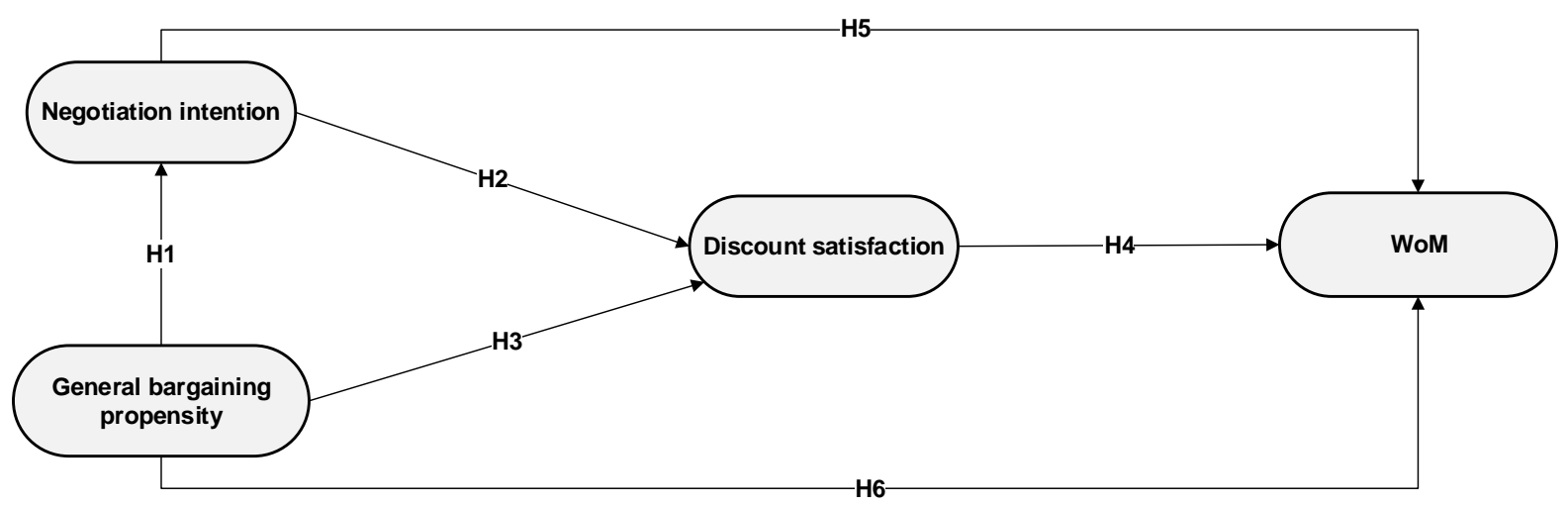

Figure 1. Conceptual framework.

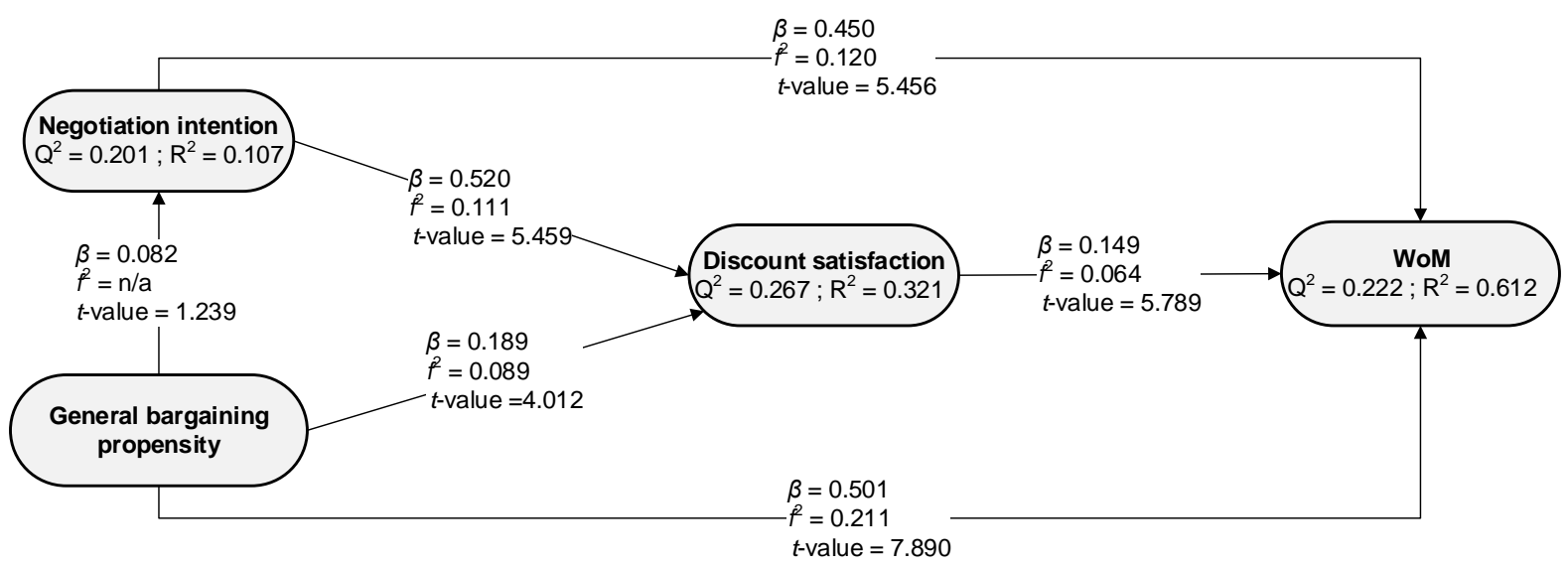

Figure 2. Structural model.

Table 1. Assessment of measurement model.

\begin{tabular}{|c|c|c|c|c|c|c|c|c|c|}
\hline Constructs & Mean & SD & $\mathrm{CR}$ & AVE & $\alpha$ & 1 & 2 & 3 & 4 \\
\hline $\begin{array}{l}\text { (1)General } \\
\text { propensity }\end{array}$ & 5.446 & 1.008 & 0.912 & 0.711 & 0842 & 0.843 & & & \\
\hline iation intention & 4.415 & 1.117 & 0.881 & 0.723 & 0.823 & 0.505 & 0.850 & & \\
\hline$(3) \mathrm{W}$ & 5.162 & 0.951 & 0.844 & 0.534 & 0.754 & 0.512 & 0.575 & 0.730 & \\
\hline (4)Discount satisfaction & 3.619 & 1.474 & 0.841 & 0.678 & 0.757 & 0.252 & 0.390 & 0.279 & 0.823 \\
\hline
\end{tabular}

Appendix 1. Constructs and items

Construct and associated items

\section{Negotiation intention}

I intended to ask for a discount prior to my purchase in the Bazaar

I intended to significantly negotiate down the price prior to my purchase in the Bazaar

I expected to realise a good price prior to my purchase in the Bazaar

General bargaining propensity

I enjoy negotiating prices

When shopping for expensive items, I look forward to the chance to bargain over the final price When shopping for even cheap items, I look forward to the chance to bargain over the final price Discount satisfaction

I am very satisfied with the discount I received at my purchase in the Bazaar

I am very satisfied with the concessions I received at this purchase 
I think I got most out of the price negotiation at this purchase WoM

I will say positive things about this Bazaar to other people

I will recommend this Bazaar to someone who seeks my advice

I will encourage friends and relatives to stay at this Bazaar

I'm likely to spread positive word-of-mouth about this Bazaar 